\title{
Erythrocyte adhesion to cultured endothelium and glycaemic control in Type 1 (insulin-dependent) diabetic patients
}

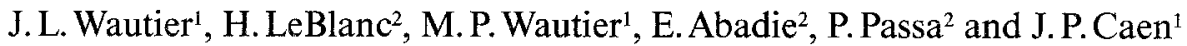 \\ ${ }^{1}$ Laboratory of Experimental Thrombosis and Hemostasis, Hôpital Lariboisière, and \\ ${ }^{2}$ Department of Endocrinology and Metabolism, Hôpital Saint-Louis, Paris, France
}

\begin{abstract}
Summary. The relation between blood glucose control and erythrocyte adhesion to cultured human vascular endothelial cells was studied in 12 Type 1 (insulin-dependent) diabetic patients. Erythrocyte adhesion was measured before, 8 days and 6 weeks after continuous subcutaneous insulin infusion (CSII). Compared to controls, erythrocyte adhesion expressed as an adhesion ratio was increased in 10 diabetic patients at the first examination (adhesion ratio >1.52). After 8 days, adhesion ratio was normalized in 5 patients. After 6 weeks, adhesion ratio was normal in 7 patients and significantly low-
\end{abstract}

er in the group of 12 patients $(p<0.01)$. The adhesion ratio was significantly correlated with glycosylated haemoglobin values $(p<0.001)$. Insulin did not directly affect erythrocyte adhesion. Adequate insulin treatment modifies erythrocyte adhesion through a metabolic effect which needs longer than 1 week to be effective.

Key words: Erythrocyte adhesion, cultured endothelium, glycaemic control, continuous subcutaneous insulin infusion, glycosylated haemoglobin.
The effect of strict blood glucose control on the evolution of microvascular complications of diabetes mellitus is still controversial [1]. New treatment regimens have been devised which permit long term control of blood glucose levels in Type 1 (insulin-dependent) diabetic patients [2]. Recently Raskin et al. [3] have reported that maintenance of nearly normal glycaemia in Type 1 diabetic patients with continuous subcutaneous insulin infusion (CSII) resulted in a normalization of microvascular lesions of skeletal muscle, although retinopathy and nephropathy were unchanged. The mechanisms responsible for diabetic microangiopathy are probably multiple. We have previously shown that adhesion to cultured vascular endothelial cells was increased in erythrocytes from patients with diabetes mellitus and that the extent of adhesion was significantly correlated with the extent and severity of vascular disease [4]. The purpose of this study was to assess the effect of insulin treatment on erythrocyte adhesion to endothelial cells after 1 week and after 6 weeks of CSII.

\section{Subjects and methods}

\section{Subjects}

Twelve Type 1 (insulin-dependent) diabetic patients were studied (mean age: $52.7 \pm 9.2$ years (mean $\pm S E M$ ), mean duration of diabetes: $15.5 \pm 8.3$ years). They all gave informed consent prior to the study. Patients with poor metabolic control, as judged by $\mathrm{HbA}_{1}$ values over $8.5 \%$, were selected. The patients were on conventional therapy consisting of twice-daily injections of intermediate-acting insulin preparations. The main clinical data are given in Table 1. Two of the diabetic patients smoked 10 to 15 cigarettes per day; the others were nonsmokers or those who had stopped smoking for at least 10 years. One patient received digitalin besides insulin. C-peptide measured by radio immunoassay was lower than $0.3 \mathrm{ng} / \mathrm{ml}$. At the time of this study the patients had already been hospitalized for a few days. CSII was started after initial investigations. Using a portable battery-powered pump (Microjet MC 20, Miles Laboratories, Inc, Elkhart, IN, USA), Actrapid insulin (Novo Industrie Pharmaceutique, Paris, France) was infused subcutaneously at basal rates with premeal supplements designed to achieve target glucose levels of 4 to $7 \mathrm{mmol} / 1$ before meals and less than $9 \mathrm{mmol} / 190 \mathrm{~min}$ after meals. A 24-h blood glucose profile was repeated after the first week of CSII. The patients were then discharged and asked to measure their blood glucose levels at least 4 times per day with a glucometer (Miles Laboratories, Inc), adjusting insulin dosage as necessary to maintain blood glucose target values. Patients were seen every 2 weeks as outpatients. The diet of the 12 patients was unchanged during the study and contained 1600 to $2200 \mathrm{cal}$ per day, including 200 to $250 \mathrm{cal}$ of carbohydrates. After 6 weeks of CSII, the patients were readmitted to measure adhesion and to check glycaemic control. Details of insulin treatment, blood glucose and $\mathrm{HbA}_{1}$ concentrations are shown in Table 2.

\section{Controls}

Normal values of erythrocyte adhesion were determined from the blood of 260 volunteers in good health. The age range was $35-67$ years, with a mean of 42.7 years. At least one normal control subject was tested simultaneously with each diabetic patient for erythrocyte adhesion to endothelial cells obtained from the same umbilical cord. 
Table 1. Clinical data

\begin{tabular}{rlllllll}
\hline No. & Sex & $\begin{array}{l}\text { Age } \\
\text { (years) }\end{array}$ & $\begin{array}{l}\text { Duration } \\
\text { of diabetes } \\
\text { (years) }\end{array}$ & Retinopathy & $\begin{array}{l}\text { Proteinuria } \\
(\mathrm{g} / 24 \mathrm{~h})\end{array}$ & Neuropathy & Peripheral vascular disease and myocardial ischemia \\
\hline 1 & M & 51 & 28 & Maculopathy & 0.64 & + & Claudication \\
2 & F & 48 & 18 & Proliferative & 3.51 & + & 0 \\
3 & M & 49 & 15 & Maculopathy & 0 & + & 0 \\
4 & M & 52 & 19 & Background & 0 & + & Claudication \\
5 & M & 67 & 14 & Maculopathy & 0 & + & Absence of both pulses in one leg \\
6 & M & 46 & 8 & 0 & 0 & 0 & 0 \\
7 & M & 48 & 29 & Proliferative & 0.60 & + & 0 \\
8 & M & 65 & 3 & Maculopathy & 0 & 0 & Absence of both pulses in one leg \\
9 & M & 50 & 16 & Background & 0.45 & + & Absence of both pulses in one leg \\
10 & M & 35 & 17 & Background & 0 & + & 0 \\
11 & M & 63 & 17 & Background & 0 & 0 & 0 \\
12 & M & 59 & 4 & 0 & 0 & & + \\
\hline
\end{tabular}

Table 2. Metabolic control

\begin{tabular}{|c|c|c|c|c|c|c|c|}
\hline \multirow[t]{2}{*}{ No. } & \multicolumn{2}{|c|}{ Insulin (IU/kg/day) } & \multicolumn{2}{|c|}{$\mathrm{HbA}_{1}(\%)$} & \multicolumn{3}{|c|}{ Blood glucose $(\mathrm{mmol} / \mathrm{l})$} \\
\hline & $\begin{array}{l}\text { Before } \\
\text { CSII }\end{array}$ & $\begin{array}{l}\text { CSII } \\
\text { (6 weeks) }\end{array}$ & $\begin{array}{l}\text { Before } \\
\text { CSII }\end{array}$ & $\begin{array}{l}\text { CSII } \\
\text { (6 weeks) }\end{array}$ & $\begin{array}{l}\text { Before } \\
\text { CSII }\end{array}$ & $\begin{array}{l}\text { CSII } \\
\text { (1 week) }\end{array}$ & $\begin{array}{l}\text { CSII } \\
\text { (6 weeks) }\end{array}$ \\
\hline 1 & 0.87 & 0.43 & 13.7 & 7.9 & 17.9 & 8.8 & 4.2 \\
\hline 2 & 1.12 & 0.69 & 10.2 & 8.7 & 18.4 & 7.5 & 5.8 \\
\hline 3 & 0.98 & 1.05 & 10.8 & 8.1 & 12.3 & 6.1 & 6.5 \\
\hline 4 & 0.53 & 0.48 & 11.4 & 8.3 & 14.7 & - & 6.5 \\
\hline 5 & 0.59 & 0.55 & 9.4 & 8.4 & 15.6 & 1.6 & 1.9 \\
\hline 6 & 0.71 & 0.68 & 10.1 & 9.0 & 21.0 & 4.5 & 8.5 \\
\hline 7 & 0.41 & 0.35 & 10.2 & 7.3 & 2.9 & 8.4 & 9.8 \\
\hline 8 & 1.52 & 0.84 & 9.7 & 6.8 & 7.4 & 6.0 & 7.5 \\
\hline 9 & 0.78 & 1.04 & 9.6 & 7.5 & 15.9 & 2.8 & 6.6 \\
\hline 10 & 0.58 & 0.46 & 10.3 & 8.5 & 14.4 & 4.1 & 10.0 \\
\hline 11 & 0.77 & 1.05 & 8.8 & 8.1 & 5.5 & 10.2 & 5.2 \\
\hline 12 & 0.91 & 0.97 & 11.7 & 8.6 & 8.9 & 8.2 & 3.7 \\
\hline
\end{tabular}

\section{Methods}

Endothelial cell culture. Endothelial cells were cultured in $35-\mathrm{mm}$ plastic dishes (Lux Scientific, Newbury, USA) according to the method of Jaffe et al. [5]. The cells from each human umbilical vein were harvested and seeded in the dishes at a concentration of 40000 per $\mathrm{cm}^{2}$. The culture medium was M 199 (Gibco, Glasgow, Scotland) containing 20 percent calf serum (Gibco). The medium was changed on day 2 and every 2 days until the cells reached confluence [6]. Cultures that did not achieve confluence, or in which detachment of cells was observed, were discarded. The endothelial cells were assessed for purity routinely by phase contrast microscopy and on several occasions by transmission electron microscopy and immunofluorescence with a specific antibody to human factor VIII related antigen (factor VIII R: Ag).

Erythrocytes. Venous blood was anticoagulated with trisodium citrate $(0.129 \mathrm{mmol} / 1$ final concentration) and the erythrocytes were washed 3 times in normal saline. The packed washed red cells were incubated at $37{ }^{\circ} \mathrm{C}$ for $40 \mathrm{~min}\left({ }^{51} \mathrm{Cr}\right)$ sodium chromate (Atom-Energy commission, Saclay, France) at a concentration of $50 \mu \mathrm{Ci}$ per millimeter. The labeled red cells were washed 4 times in Hank's balanced salt solution (HBSS) containing calcium (1.3 mmol/1) and magnesium $(0.4 \mathrm{mmol} /$ 1, Institut Pasteur, Paris, France) with human albumin ( $5 \mathrm{~g} / 1$, Centre National de Transfusion Sanguine, Paris, France) and resuspended in HBSS with albumin to give a haematocrit of 25 percent. In experiments designed to investigate the influence of insulin on adhesion, red cells were incubated with insulin $(80 \mathrm{mIu}$, Actrapid, Novo Industrie Pharmaceutique, Paris, France) for $60 \mathrm{~min}$ at $37^{\circ} \mathrm{C}$, then labelled with $51 \mathrm{Cr}$ sodium chromate.
Red cell adhesion. Erythrocyte adhesion to endothelial cells was measured as previously described in detail [4]. Briefly, labelled red cells were layered on culture plates. After incubation at $37^{\circ} \mathrm{C}$ for $30 \mathrm{~min}$, the non-attached cells were removed by aspiration and the culture plates were rinsed 5 times with $1-\mathrm{ml}$ aliquots of Hank's balanced salt solution with $5 \mathrm{~g}$ of albumin $/ 1$ (Hank's albumin). The results were expressed as the percentage of the total radioactivity that remained in the cultures after each wash according to the following formula:

Percentage of radioactivity remaining in culture $=$ $\frac{T-(R 1+R 2+R x)}{T} \cdot 100$

where $T$ denotes the total radioactivity in counts per min, $R$ the radioactivity in the wash in counts per min, and $x$ the number of the wash.

In all experiments, the total radioactivity was calculated from the sum of the radioactivity of the 5 washes plus a wash with distilled water, which removed the residual radioactivity in the dish.

To standardize the data on red cell adhesion, we also expressed the results as the adhesion ratio (AR). This ratio was defined as the percentage of radioactivity of patient red cells remaining on culture plates after the fifth wash divided by the percentage of radioactivity of control red cells remaining on simultaneously handled plates. The variability of erythrocyte adhesion has been previously reported with normal controls, with the mean AR ( \pm SD) being $1 \pm 0.26$ [4].

Glycaemic control. Glycaemic control was assessed in each diabetic patient and control subject by the mean glucose level; this represented the mean of 8 daily blood glucose as calculated before, after 1 week and after 6 weeks of CSII. 


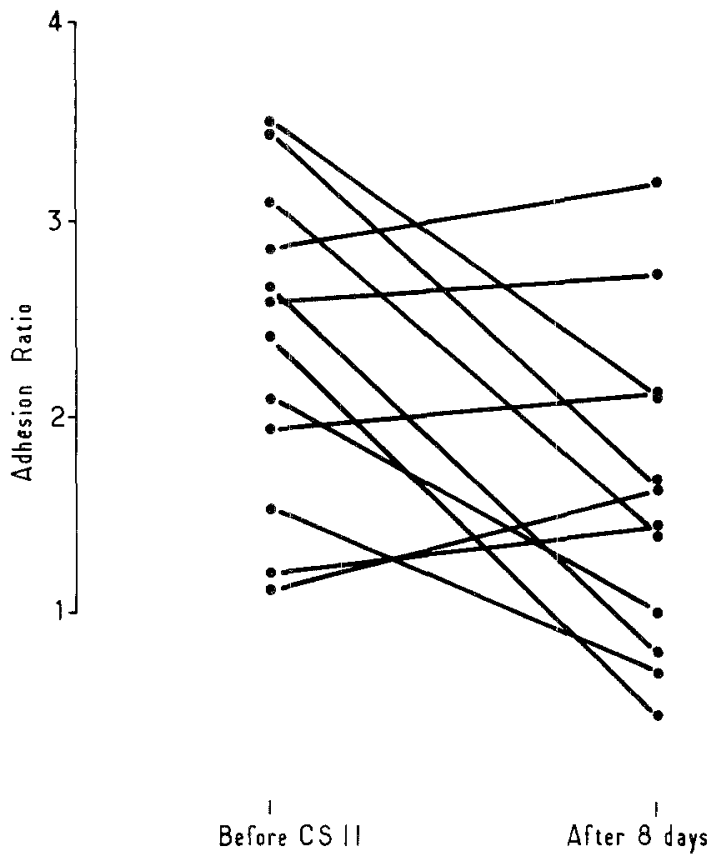

Fig. 1. Erythrocyte adhesion to endothelial cells was measured before continuous subcutaneous insulin infusion (CSII) and after 8 days of treatment. The adhesion ratio was reduced after 8 days, but was not statistically significant

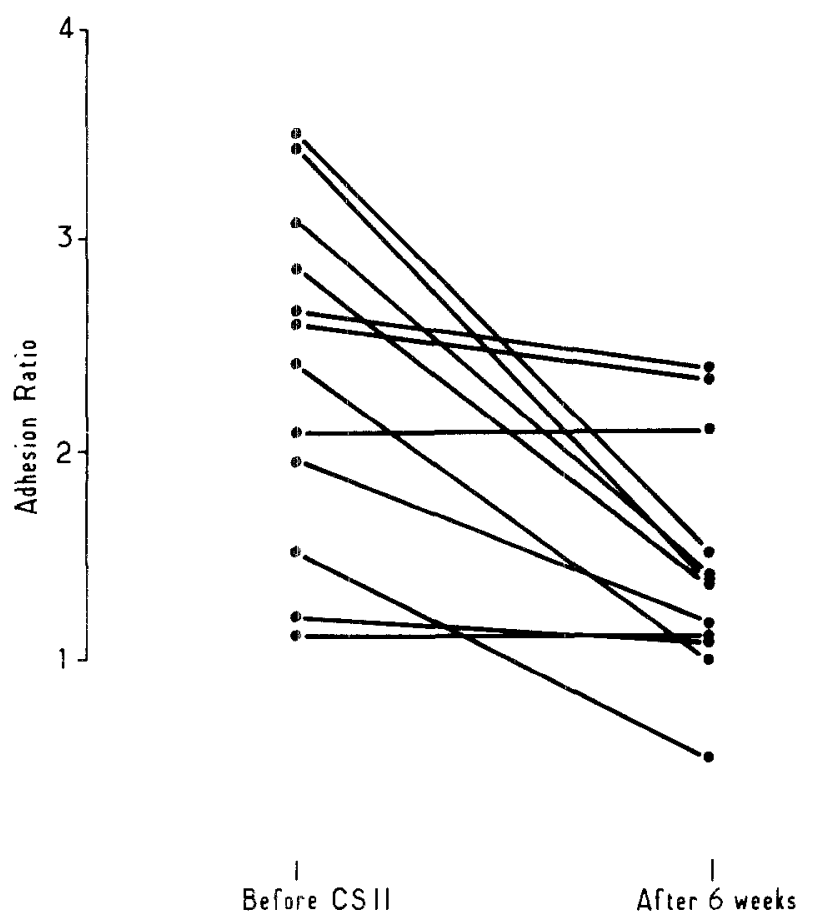

Fig. 2. Erythrocyte adhesion to endothelial cells was significantly reduced after 6 weeks of continuous subcutaneous insulin infusion (CSII) $(p<0.01)$

Haemoglobin $A_{1}$ concentration. Haemoglobin $\mathrm{A}_{1}$ was measured before and 6 weeks after CSII venous blood was collected in tubes containing fluoride EDTA. Erythrocytes were washed 3 times with $0.9 \%$ $\mathrm{NaCl}$. Glycosylated haemoglobin was determined using commercially available microcolumns (Biorad, Richmond, CA, USA) according to the method recommended by the manufacturer at constant temper- ature. In normal controls $(\mathrm{n}=30) \mathrm{HbA}_{1}$ was $6.7 \pm 0.6 \%$ (mean $\pm \mathrm{SD}$, range 6-8\%). Coefficient of variation for intra- and inter-essay runs $(n=15)$ were $4 \%$ and $5 \%$ respectively.

In vitro effect of insulin on erythrocyte adhesion. To investigate a possible effect of insulin on the adhesion of red cells to endothelium, the red cells were resuspended after washing either in Hank's buffer or in Hank's buffer containing insulin. The concentration of insulin (Actrapid MC) was varied between 8 and $80 \mathrm{mIu} / \mathrm{ml}$. The incubation time before measuring adhesion was between 2 and $30 \mathrm{~min}$. The red cells used for this type of experiment were from control subjects $(n=6)$ or from diabetic patients with an elevated $\mathrm{HbA}_{1}(n=2)$. In two diabetic patients with poor glycaemic control, the adhesion was measured in three sets of experiments; the in vitro effect of insulin was also tested. When glycaemic control was obtained, red cell adhesion was then measured and compared to the results previously obtained.

Fibrinogen concentration. Plasma fibrinogen concentration was measured using a commercial kit (Fibriprest, Stago, France) for the plasma obtained from the sample used to measure erythrocyte adhesion from normal subjects or diabetic patients.

\section{Statistical analysis}

Results were expressed as mean \pm SEM. Statistical significance was determined by the Wilcoxon's rank sum test for paired values. Correlation coefficient was calculated using a HP 86 Hewlett-Packard and a statistical program for Biomedical Statistics.

\section{Results}

\section{Glycaemic control}

The mean blood glucose level was $11.28 \pm 1.47 \mathrm{mmol} / \mathrm{l}$ before CSII, $7.79 \pm 1.00 \mathrm{mmol} / 1$ (not significant) after 1 week and of CSII $6.55 \pm 0.78 \mathrm{mmol} / 1$ after 6 weeks $(p<0.02)$. The total daily dose of insulin administered was reduced in 8 of the 12 diabetic patients. The mean daily dose of insulin was $0.83 \pm 0.32 \mathrm{IU} \mathrm{kg}^{-1}$ with conventional treatment and $0.73 \pm 0.27 \mathrm{IU} \mathrm{kg} \mathrm{kg}^{-1}$ after 6 weeks of CSII (not significant).

\section{Haemoglobin $A_{1}$}

Haemoglobin $A_{1}$ and erythrocyte adhesion were measured on two occasions: before CSII and after 6 weeks of treatment with CSII. Before CSII, the mean $\mathrm{HbA}_{1}$ level was $10.49 \pm 0.37$; after 6 weeks $\mathrm{HbA}_{1}$ was $8.35 \pm$ $0.19 \%(p<0.001)$.

\section{Erythrocyte adhesion}

At the first examination, two patients had normal erythrocyte adhesion to endothelial cells with no further significant modification throughout the study. Ten diabetic patients had an adhesion ratio which was abnormally high (AR > 1.52) before CSII was started. The highest adhesion ratio recorded was 3.50 , which corresponded to the diabetic patient with the most severe vascular complications. For this patient, the adhesion ratio after 6 weeks was improved and was at the upper limit of normal. After 8 days of CSII, the adhesion ratio was 


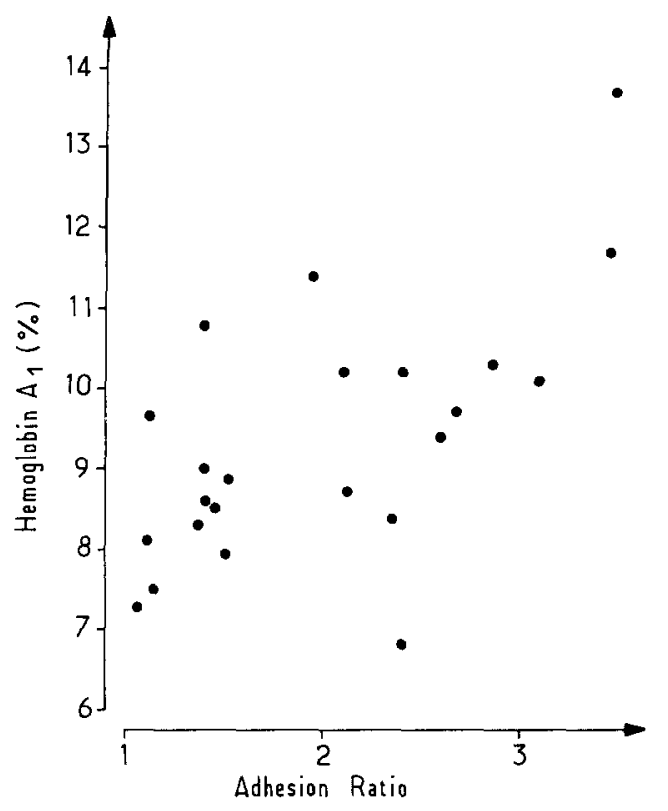

Fig.3. Erythrocyte adhesion and $\mathrm{HbA}_{1}$ concentration. Erythrocyte adhesion was lower when the $\mathrm{HbA}_{1}$ level was improved. Adhesion ratio (AR) and $\mathrm{HbA}_{1}$ concentration (in \%) were statistically correlated $(r=0.626, p<0.001)$. The normal values of AR are lower than 1.52 $($ mean $+2 \mathrm{SD})$

normalized in 5 patients, was improved but still abnormal in two patients and was unchanged in three patients. The adhesion ratio measured after at least 6 weeks of CSII was normal in 7 diabetic patients, improved but higher than the normal range in 2 patients, and unchanged in 1 patient.

As a control experiment, erythrocyte adhesion was measured on 20 occasions during a period of 18 months using the red cells obtained from the same normal subject. The mean adhesion ratio was $1 \pm 0.27( \pm S D)$.

The difference of erythrocyte adhesion before CSII and after 1 week was not statistically significant (Fig. 1). The difference in erythrocyte adhesion after 6 weeks was, however, significant (Wilcoxon's rank sum test, $p<0.01$ ) (Fig. 2).

\section{Fibrinogen concentration}

The fibrinogen concentration was measured in the plasma of the diabetic patients before and during CSII treatment. The fibrinogen level was higher in diabetic patients $(3.42 \pm 0.75 \mathrm{~g} / 1)$ than in control subjects $(2.20 \pm 0.20 \mathrm{~g} / \mathrm{l})$. The mean value of the fibrinogen concentration increased after 1 week or after 6 weeks of treatment, but the difference was not statistically significant $(1$ week $=4.35 \pm 0.94 \mathrm{~g} / 1$, 6 weeks: $4.08 \pm 0.29 \mathrm{~g} / 1)$.

\section{Erythrocyte adhesion and haemoglobin $A_{1}$ concentration}

The adhesion ratio was significantly lower when the $\mathrm{HbA}_{1}$ was under $8.5 \%(p<0.002)$. Furthermore, there was a significant correlation between the $\mathrm{HbA}_{1}$ concen- tration and the extent of erythrocyte adhesion as expressed as an adhesion ratio $(r=0.626, p<0.001$; Fig. 3).

\section{In vitro effect of insulin}

In control subjects, the addition of $80 \mathrm{mIu} / \mathrm{ml}$ of insulin to erythrocytes did not modify the adhesion to endothelial cells. The percentage of adhering red cells in the absence of insulin was $2.45 \pm 0.33(n=6$, mean \pm SEM) and $2.50 \pm 0.22$ after the addition of $80 \mathrm{mIu}$ of insulin for $30 \mathrm{~min}$. The addition of the same concentration of insulin to diabetic erythrocytes did not modify the adhesion to endothelial cells. However, the insulin treatment in the same patients was followed by a reduction in erythrocyte adhesion after 4 weeks.

These results indicate that the effect of insulin on adhesion of erythrocytes to endothelial cells is not a consequence of a direct effect of insulin on erythrocyte adhesion.

\section{Discussion}

This study showed that washed erythrocytes from diabetic patients adhered to a greater extent to cultured endothelial cells than did those from control subjects. At variance from our previous data [4], we found that the extent of red cell adhesion to endothelial cells was significantly correlated with glycaemic control assessed by glycosylated haemoglobin. This difference may be explained by the fact that our previous work was a crosssectional study of a group of patients who were in poor glycaemic control (mean Hb A1: 11.7\%). In the present prospective study with CSII, we obtained a significant improvement of glycaemic control in each patient.

There was no statistically significant relationship between the adhesion ratio and the age of the patients or the duration of diabetes, factors that are considered, with hyperglycaemia, as important determinants of the severity of diabetic vascular disease [7]. The effect of an optimalized insulin treatment on erythrocyte adhesion was statistically significant after 6 weeks of treatment. This supports the hypothesis that the abnormal erythrocyte adhesion was not immediately dependent on the elevated glucose level, since the elevated glucose level was corrected within one week. Correlation between the glycosylated haemoglobin level and the extent of the erythrocyte adhesion indicated that the modification of these two red cell parameters appear to occur during the same period of time.

This modification could be the result of the direct action of insulin on erythrocyte adhesion. This possibility seems to be eliminated in the study since the mean insulin dosage was not significantly different under conventionnal treatment or CSII. The absence of an in vitro effect of pharmacological doses of insulin on red cells from diabetic patients is in favour of an indirect ef- 
fect of insulin on red cell function or structure. We have previously reported the effect of plasma protein on adhesion to endothelium of erythrocytes from normal subjects and diabetic patients [6]. In the present study, the modification in red cell adhesion did not seem to be secondary to fibrinogen levels, since the concentration of fibrinogen was not significantly different before and after CSII. However, we cannot exclude the possibility that a modification of the fibrinogen, which is a candidate for glycosylation, could modify its reactivity as a cofactor of erythrocyte adhesion; however, its half-life appears incompatible with the absence of correction of erythrocyte adhesion after 1 week.

The results of the present study are in favour of an intrinsic abnormality of the diabetic erythrocyte. Nonenzymatic glycosylation of several proteins, including the red cell membrane glycoproteins, has been found in patients with diabetes $[8,9]$. Such a biochemical modification of the erythrocyte may account for abnormal red cell adhesion.

Red cell deformability and blood viscosity were found to be abnormal in patients with diabetes mellitus [10], and could be improved by strict blood glucose control [11] as well as abnormal erythrocyte aggregation [12]. However, controversy exists concerning the relation between blood viscosity, red cell deformability and blood glucose level or $\mathrm{HbA}_{1}$ concentration [13]. The presence of red cells is one of the required factors for the adhesion of platelets to subendothelium [14] which can only occur after endothelial damage. In diabetic patients, erythrocytes might participate in endothelial alteration and platelet deposition, both of which are involved in atherosclerotic processes.

In patients with established retinal or renal [15] diabetic microangiopathy, recent reports have failed to show a significant improvement of vascular lesions during 1- and 2-year periods of CSII treatment [15]. However, no data are actually available concerning the influence of such treatment in the early stages of the disease.

\section{References}

1. Siperstein MD, Foster DW, Knowles HC Jr, Levine R, Madison LL, Roth J (1977) Control of blood glucose and diabetic vascular disease. N Engl J Med 296: 1060-1062

2. Kitabchi AE, Fischer JN, Matteri R, Murphy MB (1982) The use of continuous insulin delivery systems in treatment of diabetes mellitus. Ann Rev Med 33: 449-90
3. Raskin P, Pietri AU, Unger R, Shannon WA (1983) The effect of diabetic control on the width of skeletal muscle capillary basement membrane in patients with type I diabetes mellitus. N Engl J Med 309: 1546-50

4. Wautier JL, Paton RC, Wautier MP, Pintigny D, Abadie E, Passa P, Caen JP (1981) Increased adhesion of erythrocytes to endothelial cells in diabetes mellitus and its relation to vascular complications. N Engl J Med 305: 237-242

5. Jaffe EA, Nachman RL, Becker CG, Minick CR (1973) Culture of human endothelial cells derived from umbilical veins: identification by morphologic and immunologic criteria. J Clin Invest 52 : 2745

6. Wautier JL, Pintigny D, Wautier MP, Paton RC, Galacteros F, Passa P, Caen JP (1983) Fibrinogen a modulator of erythrocyte adhesion to vascular endothelium. J Lab Clin Med 101: 911-920

7. Jarrett RJ, Keen H (1979) The WHO multinational study of vascular disease in diabetes. 3. Microvascular disease. Diabetes Care 2: 196-201

8. Guthrow CE, Morris MA, Day JF, Thorpe SR, Baynes JW (1979) Enhanced non enzymatic glucosylation of human serum albumin in diabetes mellitus. Proc Natl Sci USA 76: 4258-4261

9. Miller JA, Gravalles E, Bunn HF (1980) Nonenzymatic glycosylation of erythrocyte membrane proteins relevance to diabetes. $J$ Clin Invest 65: 896 -901

10. Schmid-Schonbein H, Volger E (1976) Red cell aggregation and red cell deformability in diabetes. Diabetes 25 (Suppl 2): 897-902

11. Juhan I, Vague P, Buonocore M, Moulin JP, Jouve R, Vialettes B (1982) Abnormalities of erythrocyte deformability and platelet aggregation in insulin dependent diabetics corrected by insulin in vivo and in vitro. Lancet $1: 535-537$

12. Satoh M, Imaizuim K, Bessho T, Shiga T (1984) Increased erythrocyte aggregation in diabetes mellitus and its relationship to glycosylated haemoglobin and retinopathy. Diabetologia 27: 517-521

13. Voisin PH, Kolopp M, Rouselle D, Gaillard S, Pointel JP, Stoltz JF, Debry G, Drouin P (1982) Influence du contrôle métabolique sur la viscosité sanguine et l'activité plaquettaire chez les diabétiques insulinodépendants. Nouv Rev Fr Hematol 24: $187-190$

14. Turitto VT, Baumgartner HR (1976) Platelet interaction with subendothelium in a perfusion system, physical role of red blood cells. Microvasc Res 9: 335-344

15. The Kroc collaborative study group (1984) Blood glucose control and the evolution of diabetic retinopathy and albuminuria. A preliminary multicenter trial. N Engl J Med $311: 365-372$

16. Lauritzen T, Frost Larsen K, Larsen HW, Dekert T, Steno Study Group (1983) Continuous subcutaneous insulin. Lancet 1: $1445-1446$

Received: 5 August 1985

and in revised form: 13 December 1985

Dr. J. L. Wautier

INSERM U 150

Hôpital Lariboisière

2 rue A. Paré

F-75010 Paris

France 